Review

\title{
Nanoparticle-Based Targeted Therapeutics in Head-And-Neck Cancer
}

\author{
Ting-Ting $\mathrm{Wu}$, Shui-Hong Zhou ${ }^{\bowtie}$ \\ Department of Otolaryngology, The First Affiliated Hospital, College of Medicine, Zhejiang University, 310003, China
}

$\triangle$ Corresponding author: Department of Otolaryngology, The First Affiliated Hospital, College of Medicine, Zhejiang University, 310003, China. E-mail: 1190051@zju.edu.cn; Fax: 86-571-87236895; Tel: 86-571-87236894

(C) Ivyspring International Publisher. This is an open-access article distributed under the terms of the Creative Commons License (http://creativecommons.org/ licenses/by-nc-nd/3.0/). Reproduction is permitted for personal, noncommercial use, provided that the article is in whole, unmodified, and properly cited.

Received: 2014.07.10; Accepted: 2014.12.30; Published: 2015.01.12

\begin{abstract}
Head-and-neck cancer is a major form of the disease worldwide. Treatment consists of surgery, radiation therapy and chemotherapy, but these have not resulted in improved survival rates over the past few decades. Versatile nanoparticles, with selective tumor targeting, are considered to have the potential to improve these poor outcomes. Application of nanoparticle-based targeted therapeutics has extended into many areas, including gene silencing, chemotherapeutic drug delivery, radiosensitization, photothermal therapy, and has shown much promise. In this review, we discuss recent advances in the field of nanoparticle-mediated targeted therapeutics for head-and-neck cancer, with an emphasis on the description of targeting points, including future perspectives.
\end{abstract}

Key words: Nanoparticles, targeted therapeutics, head-and-neck cancer, RNA interference, drug delivery, radiosensitization, photothermal therapy

\section{Introduction}

Head-and-neck cancer is the sixth most common cancer worldwide, with an estimated 900,000 new cases and 350,000 mortalities per year, accounting for $5-6 \%$ of all cancer cases, and affecting males more than twice as often as females [1, 2]. Almost all of these cancers are squamous cell carcinomas of the head-and-neck (HNSCC), which arise in the paranasal sinuses, nasal cavity, oral cavity, pharynx, and larynx.

Tobacco and alcohol consumption are widely accepted as the most significant risk factors for HNSCC $[3,4]$. However, infection with human papillomavirus (HPV), particularly HPV types 16 and 18, has been associated with an increase in oropharyngeal cancer in younger nonsmokers [5].

Despite recent advances in the diagnosis and treatments for patients with HNSCC, the overall outcomes and treatment-associated toxicities remain disappointing [6]. One half of newly diagnosed cases are in the advanced stages ( 3 or 4 ), leading to high death rates. The average 5-year survival rate for all stages, based on end-result data is $\sim 60 \%$. However, $50-60 \%$ of local HNSCC patients will progress to regional or distant relapses within 2 years, with a decrease in survival rate from $80 \%$ down to 50 or $35 \%$ [7]. Recurrent/metastatic patients have a median survival of less than 1 year [8].

HNSCC is a deadly and disfiguring disease, and treatment of tumors is complicated and always requires a multidisciplinary approach [9]. Surgical resection and/or radiotherapy have long been regarded as the standard treatment for HNSCC, especially in the early stages, while chemotherapy can be added as an adjunct. However, because of the complex anatomy and vital function of the facial structures, the extent of surgery will always be limited. Conventional treatments are far from perfect, either having low efficacy or resulting in severe side effects [10]. Recent researches have focused on advanced chemotherapy or radiotherapy to preserve organ function and improve the quality of life $[6,9]$. 
Nonspecific distribution is an important factor contributing to the side effects and poor clinical outcomes in conventional treatments. Targeted therapeutics, aimed at diseased tissue, have emerged as promising alternatives over conventional approaches, and overcome certain drawbacks, such as nonspecific distribution and tumor resistance. Specific antitumor effects can be achieved by blocking gene expression vital for tumorigenicity and/or tumor growth, or guiding coupled drug molecules into tumor cells in combination with an over-expressed receptor.

Nanoparticles (NPs), a class of versatile materials with diameters of 1-100 nm, can act as carriers for many drugs, imaging agents, and targeting ligands. Various types of NP have been developed as carriers for therapeutic agents, and the NP-based targeted delivery attracts more attention, which contains passive targeting and active targeting. Nano-sized particles tend to accumulate in tumor tissues, without conjugating to any tumor-specific targeting moiety; this is known as the enhanced permeability and retention (EPR) effect, which realize the passive targeting [11]. This therapeutic effect is achieved because of the abundant but leaky vasculature and impaired lymphatic drainage in tumor tissues, arising as a result of superfast growth and insufficient nutrient supply $[12,13]$. Nanoparticles, because of their small size, can extravasate through endothelium or penetrate microcapillaries of the tumors. Beyond the passive EPR effect, nanoparticles provide a surface for the attachment of specific molecular motifs to enable facilitated internalization and active tumor targeting. Indeed, nano-based active targeting has gradually attracted the focus from passive targeting systems.

Recent research has highlighted many advantages of a targeted nanomedicine approach in a combined therapy for treating HNSCC, such as enhanced preferential tumor-killing efficiency and reduced toxicity to healthy tissues [14]. This review article outlines nanoparticle-mediated targeted therapeutics for head-and-neck cancer, with the aim of identifying new approaches to improve the prognosis of patients with HNSCC. The PubMed, Web of Science, and Google Scholar databases were used.

\section{Characteristics and advantages of nano- particle carriers}

Size and size distribution are the most important characteristics of nanoparticles, determining the endosomatic distribution, biological fate, toxicity, and targeting ability [15]. Small size facilitates relatively high cell uptake. Small particles have a larger surface area-to-volume ratio, exposing more attached drugs near the surface, thus leading to a faster drug release. Larger particles have larger cores, encapsulating more drugs inside and presenting a slower release rate. So, tuning of particle size provides a means of controlling drug release rate [16].

Nanoparticles with non-modified surface can be recognized by the host immune system once in the blood stream, and massively cleared from the circulation by mononuclear phagocyte system (MPS) such as liver, spleen, lungs and bone marrow, which significantly shortens the circulation time and leads to targeting failure [17]. Novel nanoparticles coating with hydrophilic polymers/surfactants or formulating with biodegradable copolymers with hydrophilic characteristics, e.g., polyethylene glycol (PEG), can evade the human immune system [18]. PEG molecules with brush-like and intermediate configurations prevents opsonization and reduces phagocytosis [19].

The zeta potential is another useful character to describe the surface charge property and determine whether the charged load should be encapsulated within the center or on the surface of the nanoparticle. Surface zeta potential above $\pm 30 \mathrm{mV}$ prevents aggregation of the particles and stabilizes nanoparticles in suspension [20].

A successful nanodelivery system should possess a high drug-loading capacity and exhibit a controlled drug release rate, which can be modified by drug-polymer interactions, the molecular weight, solubility, diffusion, biodegradation, end functional groups in either the drug or matrix [21-23].

With the development of nanotechnology, various types of NP have been applied in medical field to carry therapeutic agents. Liposomes are one of the most widely used carriers, acting as "contact-facilitated drug delivery", which displays as when binding or interacting with the targeted cell membrane, the lipid-lipid exchange with the lipid monolayer of the nanoparticle enhances, thus accelerateing the convective flux of lipophilic drugs (e.g., paclitaxel) to dissolve through the outer lipid membrane of the nanoparticles to targeted cells membrane [24]. Block-copolymer micelles (e.g. poly(amino acid)) are amphiphilic nanospheres assemblized with a hydrophobic core available for accommodating lipophilic drugs and a hydrophilic brush-like coronal shell to make the micelle water soluble and prolong their circulation time, thereby suitable for delivery of the poorly soluble contents [25].

Degradable polymersomes are hollow shell nanoparticles with thick membranes comprised of two layers of synthetic polymers and an aqueous lumen, tending to break down in the acidic environment and release drugs within tumor cell endosomes, which is called pH-triggered release [26]. Polymersomes have been used to encapsulate paclitaxel and doxorubicin for passive delivery into cancer cells. Paclitaxel, which 
is water insoluble, embeds within the shell of polymersomes. While doxorubicin, which is water-soluble, stays within the interior lumen of the polymersome until it degrades. The combination of polymersome and drug spontaneously self-assembles when mixed together. The cocktails of paclitaxel and doxorubicin lead to significant tumor regression [27].

Single-walled carbon nano-tubes (SWCNTs) are synthesized by covalently attaching multiple copies of tumor-specific monoclonal antibodies, radiation ion chelates and fluorescent probes [28], overcoming the limitation of impeded targeting ability resulted from too much chemical bonds interacted between antibody and drug molecules, showing great potential to carry multiple drug payloads. Multidrug resistance (MDR) of tumor cells developed through a variety of molecular mechanisms is a serious problem in chemotherapy. Attacking tumors with more than one kind of drugs at a time can reduce the possibility of their escaping from treatment and overcome MDR [29].

.Programmed drug delivery, named from the ability to alter the structure and properties of nanocarriers when delivering, can be achieved by incorporating of molecular sensors that respond to physical or biological stimuli, including changes in $\mathrm{pH}$, redox, potential, or enzymes [30]. Nanomaterials have emerged to create a promising drug-delivery system with advantages like enhanced stability, ease of surface modification, surface for targeted delivery, improved bioavailability, sustained drug release and assistant to solubilize drugs for systemic delivery.

\section{Antisense oligonucleotides (ASOs)}

The activity of oncogenes-including, myc, fos, ras and certain viruses such as HSV-1 and HPV-is important in tumorigenicity. Aberrant activation of oncogenes evokes a complex network of signaling pathways that interfere with biological systems, and blocking any of the conducting molecules in a relevant network may inhibit tumor growth.

Antisense oligonucleotides (ASOs) are an appealing gene-silencing strategy; they are induced by a single strand of oligonucleotides, targeted at the complementary region of the oncogene mRNA by Watson-Crick base pairing, and can downregulate oncogene expression and abrogate tumor growth [31]. The mechanism is associated with the activation of endogenous ribonuclease $\mathrm{H}$ and subsequent exonuclease cleavage of the associated mRNA [32].

The major limitation of ASO-mediated gene silencing therapy is the difficulty in delivering a sufficient quantity of antisense molecules into tumor cells. Introducing a phosphorothioate backbone improves the stability of the ASOs, but there are accompanying drawbacks, such as increased toxicity and diminished affinity for the target sequence [33]. The 2'-methoxyethyl modified second-generation phosphorothioate ASOs have shown higher efficacy in cancer gene therapy, and are at present undergoing clinical trials [34].

Carriers for ASOs can be categorized into two groups; natural (viruses and bacteria) and nonviral. Viral vectors provide efficient delivery but also have several drawbacks, such as insertional mutagenesis and immunogenicity [35]. In contrast, nonviral carriers are safer and easier to produce. Cationic liposomes (e.g. Lipofectamine ${ }^{\circledR} 2000$ ) have been trialed and are some of the most widely used nonviral nanocarriers for ASO delivery; they have low toxicity, are non-immunogenic, only slightly inflammatory, and are easier to obtain than viral vectors, while their chief disadvantages consist of relatively low transfection efficiency and/or a shortened effective gene silencing time [36]. Cationic liposomes increase nucleic acid uptake into cells compared to standard liposomes, with minimal toxicity [37].

\subsection{Glucose transporter-1 (Glut-1)}

Malignant cells exhibit increased glucose consumption and lactate production, even under normal oxygen conditions, known as the Warburg effect, or aerobic glycolysis [38, 39]. The Warburg effect has received increased attention lately, especially following the rapid development of FDG-PET (FDG, fluorodeoxyglucose) for tumor imaging [40]. The glucose transporter-1 (Glut-1) is a membrane protein that facilitates the intracellular uptake of glucose. Elevated expression of Glut-1 has been observed in several cancer types and has been identified as a valuable prognostic indicator [41-43]. In several experiments, Glut-1 expression was correlated with lymph node metastasis, poor survival, and clinical stage HNSCC, and increased Glut-1 expression can be an independent predictor of survival in laryngeal carcinoma $[44,45]$.

Recently, the crystal structure of human Glut-1 was identified as in an inward-open conformation. This major breakthrough serves as a basis for understanding the functional mechanism of Glut-1 and for the development of potential targeted therapeutic agents [46].

A pcDNA3.1(+) eukaryotic expression system vector containing the antisense Glut-1 gene was constructed, followed by successful transfection into Hep-2 laryngeal carcinoma cells [47]. Another study investigated the biological effects of plasmid-derived antisense RNA against the Glut-l gene in Hep-2 cells, and reported inhibited proliferation and decreased glucose uptake [40]. 


\subsection{Epidermal growth factor receptor (EGFR) and Stat3}

He et al. investigated the intratumoral transfer of cationic liposome-mediated antisense EGFR plasmids into HNSCC subcutaneous xenografts, which resulted in suppression of EGFR protein expression, increased tumor cells apoptosis, and inhibition of tumor growth [48]. Grandis et al. aimed to demonstrate that EGFR-mediated Stat3 activation contributed to the uncontrolled acceleration of tumor growth by an anti-apoptosis mechanism, and found that inhibition of Stat3 activation via a liposome-mediated Stat3 antisense plasmid resulted in inhibited tumor growth and stimulated apoptosis in HNSCC xenograft models [49, 50].

Intratumoral administration of antisense oligonucleotides showed an antitumor effect in xenograft models of squamous cell carcinoma of the head-and-neck $(\mathrm{SCCHN})$, but limited clinical application. Studies underway at present aim to improve systemic administration [51].

\subsection{CK2 and NF-KB}

Protein kinase CK2 consists of two catalytic subunits (42 kDa a, $\left.38 \mathrm{kDa} \mathrm{a}^{\prime}\right)$ and a regulatory subunit $(28 \mathrm{kDa} \beta)$, and forms holoenzyme tetramers such as $\alpha 2 \beta 2$, aq' $\beta 2$,or a' $2 \beta 2$ [52]. CK2 plays a key role in many diseases, including prostate, breast, kidney, and lung cancers, via modulation of cell proliferation and differentiation and anti-apoptosis mechanisms [53, 54]. CK2 is elevated in HNSCC, and is associated with aggressive tumor behavior and a poor prognosis, indicating that it may be an effective therapeutic target $[53,55]$. Brown et al. reported the antitumor effects of anti-CK2 $\alpha / \alpha^{\prime}$ oligodeoxynucleotide (ODN) encapsulated in sub-50-nm tenfibgen-based nanocapsules in HNSCC xenograft models, which was accompanied by suppression of NF-kB and modulation of the expression of key genes [56].

\subsection{Transforming growth factor alpha (TGF- $\alpha$ )}

TGF-a is a polypeptide that interacts with EGFR [57]. Over-expression of TGF-a alone, or highly co-expressed TGF- $\alpha$ and EGFR, has been implicated in the oncogenesis of many cancers, including HNSCC, and is an independent prognostic factor for the survival of patients with primary HNSCC $[58,59]$. In vitro studies have shown that downregulation of TGF-a expression via ASOs successfully inhibited proliferation of HNSCC [60]. Endo et al. examined the antitumor effects of cationic liposome-mediated antisense human TGF-a in a HNSCC xenograft model, and reported positive results [61].

\subsection{Survivin}

Survivin is a member of the inhibition of apoptosis (IAP) gene family, prominently expressed in all common human cancers, but barely expressed in normal adult tissues [62]. Survivin has multiple functions, including inhibition of apoptosis and cell-cycle regulation, and plays a key role in carcinogenesis and tumor progression [63]. Overexpression of survivin occurs in HNSCC and is regarded as a prognostic marker [64, 65]. Xiang et al. transformed survivin-ASOs via liposomes into the Hep2 human laryngeal carcinoma cell line, which resulted in significant downregulation of survivin gene expression and protein levels, and enhanced antitumor effects in vitro and in vivo [66].

\section{RNA interference (RNAi)}

Investigation into the use of RNAi, another attractive possibility for cancer gene therapies, has been conducted increasingly since the award of the Nobel Prize in 1998 [67]. RNAi is defined as post-transcriptional gene silencing, initiated by approximately 21- or 22-nucleotide double-stranded RNAs (dsRNA) with a sequence homologous to that of the targeted gene [68]. The small interfering RNA (siRNA) incorporates into the RNA-induced silencing complex (RISC) upon reaching the cytoplasm, where the duplex is separated and one strand guides the RISC to combine with the targeted mRNA, bearing an exact complementary sequence. This perfect match results in degradation or translation blockage of mRNA, thus inhibiting expression of the relevant gene [69-71].

siRNA and ASOs function by inducing degradation of targeted messenger RNA. The gene silencing efficacy of duplex siRNAs and single-stranded antisense RNA is at present undergoing evaluation. Bertrand et al. compared the efficacies of antisense RNA and siRNA delivered by Grassy Stunt Virus (GSV) in a HeLa cell culture and in xenografted mice; siRNA was more effective, possibly due to enhanced resistance to nuclease degradation due to the formation of the RISC [72]. Xu et al. found that double-stranded siRNAs exhibited higher gene silencing efficacy than ASOs when targeted to multiple sites of exogenous luciferase mRNA and endogenous CD46 mRNA in mammalian cells [73]. However, Holen et al. reported that ASOs were less effective in reducing targeted mRNA (Human Tissue Factor) expression, but reached a peak faster than the duplex siRNA in HaCaT cells. As an excess of inactive double-stranded siRNA competed in a sequence-independent manner with ASOs, it was concluded both gene silencing strategies shared a pathway [74]. 
RNAi-based technology has shown great potential in targeted cancer therapy by suppressing the expression of genes associated with tumor growth [75]. Other molecular targets with a high specificity for HNSCCs have also been investigated, such as epidermal growth factor receptor (EGFR) and folic acid. The interference activity of siRNA occurs primarily in the cytoplasm. However, siRNAs cannot readily pass through the cell membrane due to their high molecular weight and negative charge. Furthermore, after systemic administration, nonspecific distribution of siRNA decreases local concentrations, serum RNase rapidly hydrolyzes naked siRNA, and rapid renal excretion and unexpected reticuloendothelial uptake further reduce its effective duration [76, 77]. Therefore, a multi-functional delivery system that protects and introduces siRNA into targeted cells is important for successful gene knockdown. Nanotechnology has been applied to assist siRNA delivery and has increased its stability and facilitated its introduction into malignant cancer cells [78, 79].

\subsection{Epidermal growth factor receptor (EGFR)}

EGFR, a member of the ErbB receptor family (Her-1, Her-2, Her-3, and Her-4), is composed of an extracellular ligand-binding domain, a hydrophobic transmembrane segment, and an intracellular tyrosine kinase (TK) domain. The extracellular domain provides a binding site for the endogenous ligand, epidermal growth factor (EGF) or TGF-a, and the binding interaction induces subsequent receptor-mediated internalization and auto-activation of intracellular tyrosine kinase (TK), which is closely related to other vital intracellular signaling pathways [80].

Over-expression of EGFR is detected in over 90\% of HNSCC cases and is associated with a poor treatment response and a worse prognosis [80, 81]. An increase in EGFR has been implicated in oncogenicity through activation of a series of aberrant downstream cell proliferation signaling pathways, differentiation, anti-apoptosis, and invasiveness [82]. Hence, inhibiting the function of EGFR to interrupt the mechanisms of tumor growth by siRNA technology has attracted much attention. Cho et al. investigated a polyelectrolyte nanocomplex composed of PLR and DEX for the delivery of EGFR-siRNA in an HNSCC model. Results showed an increased efficiency in EGFR-siRNA cell uptake and EGFR gene silencing in Hep-2 and FaDu cells, and efficient tumor growth inhibition in vivo [83].

\subsection{Ribonucleotide reductase M2 (RRM2)}

RRM2, is the M2 subunit of ribonucleotide reductase (RR), and expression is increased 3-7-fold when cell the cycle passes from the G1- to S-phase; it plays a critical role in DNA synthesis by modulating the enzymatic activity of RR in the conversion of ribonucleotide 5 '-diphosphates to 2'-deoxyribonucleotides [84, 85]. Overexpression of RRM2 and the subsequent elevated RR activity are associated with tumorigenesis and tumor progression, suggesting that RRM2 could be a potential target for tumor diagnosis and therapy. Recent research has indicated some success in using RRM2-siRNA against a wide range of tumors, including non-small-cell lung cancer (NSCLC), pancreatic adenocarcinoma, bladder cancer, leukemia, and some solid tumors [86].

CALAA-01 is a nano-sized siRNA therapeutic that contains: (i) a liner, cyclodextrin-based polymer (CDP), (ii) human transferrin protein (hTf) ligands displayed on the surface as the targeting moiety to engage transferrin receptors (TfR), (iii) a hydrophilic polymer used to stabilize nanoparticles in biological fluids, and (iv) siRNA targeting to RRM2 [87]. TfR is upregulated in malignant cells, and use of the hTf moiety in the delivery system helps to achieve more specific and efficient delivery of siRNA [88, 89]. The CALAA-01 delivery system has had positive anti-tumor results and has been shown to be safe in many cancer models. The first siRNA clinical trial is underway (clinical trial registration number, NCT00689065) to test the effectiveness of CALAA-01 in systemic delivery of siRNA in patients with solid cancers [87].

Rahman et al. successfully delivered RRM2-siRNA via CALAA-01 nanoparticles to suppress HNSCC tumor growth both in vitro and in vivo, without any signs of adverse effects or toxicity [90]. The underlying mechanisms were also investigated, and degradation of Bcl-2 was identified as the key determinant in tumor cell apoptosis [91].

\subsection{Human rhomboid family 1 gene (RHBDF 1 )}

The rhomboid family of genes is highly conserved, encoding a group of seven transmembrane proteins which function in diverse processes, including protein cleavage, signaling pathway modulation $[92,93]$, apoptosis [94], mitochondrial membrane fusion [95], endoplasmic reticulum-associated degradation [96], and others. Recent research has highlighted a connection between the RHBDF1 gene and a variety of human diseases, such as leukemia [97] and breast cancer [98], and research into gene silencing therapies is ongoing [99]. The RHBDF1 gene is the first member of the rhomboid family. It is located on the endoplasmic reticulum and the Golgi apparatus, and interacts with TGF-a ligands, which is followed by EGFR activation [100].

Yan et al. demonstrated that elevated expression of RHBDF1 was essential in epithelial cancer cell 
growth. Silencing the RHBDF1 gene with siRNAs resulted in apoptosis in breast cancer MDA-MB-435 cells, and autophagy in HNSCC1483 cells, probably caused by the downregulation of activated AKT and other extracellular growth signals. Additionally, systemic administration using a histidine-lysine polymer (HKP) nanoparticle delivery system increased the deposit of RHBDF1-siRNA in MDA-MB-435 and 1483 xenograft tumors, which led to marked gene silencing and inhibition of tumor growth, compared to nude siRNA [101]. Zou et al. found that RHBDF1 participated in $G$ protein-coupled receptor (GPCR)-mediated transactivation of latent EGFR ligands in HNSCCs [102].

\section{Immunotherapy}

\section{Epidermal growth factor receptor (EGFR)}

There are two complementary strategies in EGFR immunotherapy; monoclonal antibodies (e.g., Cetuximab; CET) and small molecular TK inhibitors (e.g., Erlotinib). CET (Erbitux), a chimeric (mouse/human) IgG monoclonal antibody that binds exclusively to EGFR and blocks its function through competitive inhibition, has been approved by the U.S. Food \& Drug Administration (FDA) for treatment of colorectal and lung cancers, and HNSCC. TK inhibitors target the intracellular domain of EGFR, competing with adenosine triphosphate (ATP) for binding sites. Though immunotherapy alone has exhibited a limited effect in clinical practice in treating HNSCC, a combination with other therapeutic methods has yielded some positive results [103] [104].

Albumin is an essential carrier for binding and transporting various functional molecules throughout the circulatory system. Recently, nanosized formations of albumin have shown promise as a drug-delivery system. The glutaraldehyde cross-linked albumin nanoparticle is $\sim 100 \mathrm{~nm}$ in diameter. Altintas et al. modified the surface of the albumin nanoparticles with bifunctional PEG 3500 and a nanobody (EGa1) against EGFR, which showed 40-fold greater affinity to EGFR-positive HNSCC 14C cell lines compared to PEGylated cells. The EGa1-PEG functionalized nanoparticles were used to deliver multikinase inhibitor 17864-Lx, a platinum-bound sunitinib analogue, which resulted in a constant rate of drug release and an antiproliferative effect on $14 \mathrm{C}$ cells [105].

\section{DRUG DELIVERY}

Chemotherapy is generally used alongside surgery and/or radiotherapy in advanced cancer cases. The most common chemotherapeutic agents used are platinum-based drugs (cisplatin or carboplatin) and combinations with taxanes (e.g., docetaxel) or 5-fluorouracil. However, conventional delivery methods of chemotherapeutic agents have several limitations: Firstly, some drugs have poor solubility and low bioavailability and contain toxic solvents in their formulation. Secondly, they have a short circulation time because of their physiological instability, degradation, and clearance. Thirdly, the nonspecific distribution of the drugs limits the concentration achieved in the tumor, and causes harmful side-effects because of their unwanted accumulation in healthy tissues. Clinical studies revealed that approximately $30 \%$ of patients with advanced HNSCC responded to a single agent, such as cisplatin or 5-FU, but no improvement in overall survival was observed [106]. A combination of chemotherapeutic agents did improve the drug response but had no effect on overall survival [107]. Therefore, advanced drug delivery systems (DDS), based on nanotechnology and a tumor-targeted strategy, hold considerable potential to enhance chemotherapeutic efficacy.

\section{Passive targeting}

Passive diffusion is the major internalization mechanism of free drugs into tumor cells, which tends to activate the efflux pump and removes drugs from the cells. Fortunately, nano-sized complexes can be internalized by tumor cells via endocytosis, thus avoiding the increased efflux pump mechanism and reducing drug resistance [29]. Zhou et al. developed a series of amphiphilic chitosan derivatives by grafting deoxycholic acid and hydrophilic molecules, with sizes of 160-240 nm, for loading of the hydrophobic drugs, paclitaxel (PTX) and doxorubicin (DOX). These nanoparticles showed sustained and controlled drug release, the rate of which could be adjusted by changing the degree of substitution (DS) of deoxycholic acid and hydrophilic molecules, and the $\mathrm{pH}$ of the release medium [108]. Several nanoparticle formulations of chemotherapeutic agents have been approved for clinical use; Abraxane is a nanoparticle formulation of albumin and paclitaxel, and Genexol-PM is a polymeric nanoparticle formulation of paclitaxel.

\section{Active targeting}

As described previously, nanoparticles provide suitable attachment sites for targeting moieties. By interacting with overexpressed receptors or via specific expression on the surface of targeted cancer cells, functionalized nanosystems could further improve the efficacy and specificity of drug delivery systems. Research is concentrated on identifying more specific receptors and effective nanosystems (Table 1). 
Table 1. An overview of targeted nanodevices for drug delivery in head and neck cancer management

\begin{tabular}{|c|c|c|c|c|}
\hline Targeting antigen & $\begin{array}{l}\text { Targeting moiety } \\
\text { antibody }\end{array}$ & Nano-platform & Drug & Ref. \\
\hline \multirow[t]{5}{*}{ Folate receptor } & folic acid & heparin-folic acid-paclitaxel (HFT) & paclitaxel & [113] \\
\hline & folic acid & acetylated generation 5 dendrimers & methotrexate & {$[114]$} \\
\hline & folic acid & magnetic nanoparticles & cisplatin & [115] \\
\hline & folic acid & Albumin & paclitaxel & [118] \\
\hline & folic acid & $\begin{array}{l}\text { Liposome } \\
\text { (plus antisense HER-2) }\end{array}$ & $\begin{array}{l}\text { cisplatin, taxotere, } \\
\text { doxorubicin, 5-fluorouracil }\end{array}$ & [133] \\
\hline \multirow[t]{2}{*}{ EGFR } & EGF & SWNTs & cisplatin & [119] \\
\hline & Cetuximab & $\begin{array}{l}\text { carbon nanoparticle } \\
\text { (ps: noncovalent assembly ) }\end{array}$ & paclitaxel & [103] [104] \\
\hline \multirow[t]{3}{*}{ Mcl1 } & Mcl1 siRNA & lipid nanoparticles & mitoxantrone & [123] \\
\hline & Mcl1 siRNA & lipid nanoparticles & paclitaxel & [124] \\
\hline & Mcl1 siRNA & lipid nanoparticles & SAHA & [125] \\
\hline CK 2 & CK 2 siRNA & liposome & cisplatin & {$[56]$} \\
\hline Survivin & Survivin siRNA & $\begin{array}{l}\text { liposome } \\
\text { (plus iNOS-specific inhibitor } 1400 \mathrm{~W} \text { ) }\end{array}$ & paclitaxel & [134] \\
\hline
\end{tabular}

Abbreviations: HFT, heparin-folic acid-paclitaxel; EGFR, epidermal growth factor receptor; EGF, epidermal growth factor receptor; HER-2, human epidermal-growth-factor receptor 2; SWNTs, single-walled carbon nanotubes; Mcl1, myeloid cell leukemia sequence 1; SAHA, suberoylanilide hydroxamic acid; iNOS, inducible NO synthase

\subsection{Folate receptor}

Folate receptors (FRs) are glycosylphosphatidylinositol-anchored cell surface receptors with a high affinity for folic acid (FA). Though FRs are present throughout the body and have important physiological functions, they are highly expressed in a wide range of malignant cancers, such as breast, ovarian, lung, kidney and HNSCC [109]. FA is a water-soluble $B$ vitamin, critical for DNA synthesis, and has potential as a ligand for targeted drug delivery, in terms of its low molecular weight (441 Da), stability, non-immunogenicity, and ease of synthesis. FA retains its ability to bind with FRs after conjugation with other structures, and can then be transported into cells through the FR-mediated endocytosis pathway [110]. FRs are one of the most widely investigated receptors for the targeting of drug delivery systems to FR-positive tumors [111]. Overexpression of FRs occurs in approximately half of primary HNSCCs and correlates with a worse clinical outcome, indicating a promising role for FR in targeted delivery in HNSCC patients [112].

Wang et al. synthesized a ternary conjugate heparin-folic acid-paclitaxel (HFT), loaded with additional paclitaxel $(\mathrm{T})$, to improve the antitumor efficacy and specificity of paclitaxel for the FR-positive HNSCC KB-3-1 cell line in vitro and in vivo. The resulting nanoparticle, HFT-T, selectively recognized FR-positive cancer cells and markedly inhibited tumor growth compared to the free form of paclitaxel, without showing a resurgence of tumor growth after several weeks' treatment [113]. Ward et al. conjugated methotrexate and folic acid to acetylated generation 5 dendrimers, which significantly increased its chemotherapeutic performance in HNCSS in vitro and in vivo [114]. This is the first instance of dendrimers being used as a platform for loading targeting moieties and therapeutic drugs. Xie et al. developed a folate-conjugated cisplatin-loaded magnetic nanomedicine (CDDP-FA-ASA-MNP), which provided an alternative platform for drug delivery in HNSCC patients [115].

Dosio et al. conjugated paclitaxel to human serum albumin (HSA), which increased the performance of paclitaxel in three tumor cell lines, with slower elimination, continuous drug release, high cytotoxicity, and reduced systemic toxicity compared to the free drugs [116]. Further research showed that surface modification by covalent linkage of polyethylene glycol (mPEG) provided a shield, and further reduced clearance and organ uptake [117]. Folic acid was added as a targeting ligand based on previous paclitaxel-albumin mPEG derivatives. The resulting folate-mediated paclitaxel-loaded albumin complexes demonstrated increased selectivity and anti-tumor efficacy in the human nasopharyngeal epidermal carcinoma KB cell line [118].

\subsection{Epidermal growth factor receptor (EGFR)}

As described in the section on siRNA delivery above, EGFR can also provide a target for chemotherapeutic drug delivery. Ashwin et al. demonstrated that EGF-directed single-walled carbon nanotubes (SWNTs), as a delivery system for cisplatin chemotherapy, resulted in more specific and rapid drug internalization into HNSCC cells, and distinct tumor growth regression compared to a non-targeted SWNT-cisplatin control. Knockdown of the EGFR gene by siRNA blocked the accelerated drug uptake, which confirmed the importance of the EGF-EGFR interaction in this delivery system [119]. Carbon nanotubes are considered to be suitable transporters 
for drug delivery, having a unique size, shape and physical properties [120].

Berlin et al. reported another EGFR-targeted carbon nanoparticle for drug delivery. All three if its components, a PFG-functionalized carbon nanovector, CET and paclitaxel, were assembled through noncovalent interactions by simple physisorption, which is essential in creating personalized medicines [103]. A previous report revealed the equivalent cytotoxicity of noncovalent paclitaxel-loaded carbon nanoparticles when added to a commercial formulation of paclitaxel (PTX/Cremophor, solution of PTX in Cremophor) [121]. The addition of CET, a monoclonal antibody targeted to EGFR, facilitated the specific uptake of paclitaxel by EGFR+ cells (OSC-19) in vitro [103]. In a FaDu -and OSC-19- cell-derived orthotopic model of tongue cancer, this novel targeting delivery system showed marked anti-tumor activity but disappointingly, no significant difference compared to the other PTX treatment groups was observed [104].

\subsection{Myeloid cell leukemia sequence 1 (Mcl1)}

Mcl1, belongs to the Bcl-2 family of apoptosis-regulating proteins, and exerts a negative effect on apoptosis-induction resulting from chemotherapeutic agents [122]. Cationic lipid nanoparticle-based Mcl1-siRNA loading with mitoxantrone showed enhanced antitumor activity compared to Lipofectamine ${ }^{\circledR}$ 2000-mediated transfection of siMcl-1 [123]. Yu et al. loaded cationic lipid nanoparticles with PTX and Mcl1-siRNA and observed the highest cellular uptake and antitumor effect using nanoparticle-based Mcl1-siRNA, followed by nanoparticle-based PTX, PTX, and siRNA, in human epithelial carcinoma KB cells [124]. Trilysinoyl oleylamide-based cationic liposomes were synthesized for the co-delivery of the anticancer drug, suberoylanilide hydroxamic acid (SAHA), and in this case Mcl1-siRNA also showed positive results [125].

The mitogen-activated protein/extracellular signal-regulated kinase kinase (MEK) inhibitor blocks the Raf/MEK/extracellular signal-related kinase (ERK) pathway and is involved in proliferation and anti-apoptosis [126, 127]. Kang et al. formulated $\mathrm{N}^{\prime}$, $\mathrm{N}^{\prime \prime}$-dioleylglutamide (DG)-containing liposomes for co-delivery of siMcl1 and the MEK PD0325901 inhibitor, which showed enhanced antitumor activity [128].

\section{Chemosensitivity}

Chemo-resistance is a biological response resulting from various signaling pathways, such as inhibition of apoptosis and DNA repair, and is associated with elevated levels of key molecules such as EGFR, VEGF, IGF, Mcl-1 etc. Downregulation of relevant signaling molecule expression via a specific gene silencing strategy enhances the chemotherapeutic efficacy in HNSCC [129-132]. Neither chemotherapeutic drugs nor nucleic acids alone can completely eradicate NHSCC, but a combination may prove effective. Synergistic effect mechanisms from nucleic acids not only inhibit certain targeting antigen by complementary sequences, but also guide the drugs into the tumor cells.

Rait et al. investigated phosphorothioate pentadecamer ASOs targeted to HER-2 mRNA (antisense HER-2), complexed with a folate-liposome delivery system, to improve the sensitivity to four chemotherapeutic drugs (cisplatin, taxotere, doxorubicin, and 5-fluorouracil) of a low HER-2-expressing and cisplatin-resistant SCC-25CP cell line. Results showed that folate-targeted liposome formation significantly increased intracellular ASOs uptake compared to a lipofectin carrier and free ASOs, accompanied by decreased HER-2 protein levels and increased apoptosis. The combination of a folate-liposome with HER-2 and chemotherapeutic agents showed a synergistic antitumor effect, resulting in increased apoptosis. In addition, confocal microscopy revealed that ASOs accumulated mainly in the cell nuclei, while liposomes remained in the cytoplasm after internalization [133]. This study showed that folate-targeted liposome-mediated antisense HER-2 was a potential chemosensitizer in HNSCC, and over-expression of HER-2 was not necessary.

The research using anti-CK2a/ $\alpha^{\prime}$ oligodeoxynucleotides (ODNs) described above, also revealed that knockdown of the CK2 subunits via a specific siRNA, differentially decreased cell proliferation, inhibited cell migration, and enhanced the sensitivity to cisplatin in UM-SCC cell lines. Additionally, CK2a had the greatest effect on modulating proliferation, apoptosis, migration, malignant phenotype and chemosensitivity to cisplatin, while other CK2 subunits showed varying effects on regulation of the cell cycle, migration, and angiogenesis [56].

Fetz et al. reported that a combination of survivin-siRNA and an inducible NO synthase (iNOS) -specific inhibitor, $1400 \mathrm{~W}$, cooperatively enhanced the chemotherapeutic effects of PTX for HNSCC [134].

\section{Radiosensitization}

Radiotherapy (RT) is applied widely for primary or adjuvant treatment of HNSCC, with a high tumor control and cure rate, especially in early stage cancer. Despite its benefits, the dose-related treatment toxicity limits the efficacy of RT, which has serious side effects. Moreover, resistance to RT is another problem, which often results in treatment failure. The overall survival rate is only $20 \%$ for patients with unresectable tumors treated with radiotherapy alone. The 
current clinical strategy for radiosensitization is use of a combination of RT with chemotherapeutics, such as docetaxel (Dtxl), carboplatin; however, this is associated with unacceptable levels of systemic toxicity $[135,136]$. Considering the drawbacks of conventional chemo-radiotherapy, targeted nanomedicine represents a promising alternative. (Table 2)

\subsection{Glucose transporter-1 (Glut-1)}

The exact mechanisms of radioresistance in laryngeal carcinoma remain unclear. Malignant cells frequently encounter a hypoxic microenvironment due to excessive tumor growth. Several studies have shown that GLUT-1 is associated with the malignant glucose metabolism and increased FDG uptake, and predict the hypoxic status of cancer [137-140]. Over-expression of GLUT-1 may be a metabolic marker of radioresistance and an adverse prognosis $[141,142]$. This was assessed in laryngeal carcinoma Hep-2 cells, and the results showed a significant difference in GLUT-1 mRNA and protein levels before and after X-ray radiation. Cell survival rates were significantly decreased with increasing doses of radiation and the GLUT-1 ASOs transfection time. In an in vivo study, GLUT-1 mRNA and protein levels were reduced after 8-Gy radiation combined with transfection of GLUT-1 ASOs, compared to 8-Gy radiation alone [143]. In conclusion, GLUT-1 ASOs have the potential to act as radiosensitizers for laryngeal carcinoma. It may be possible to use nanotechnology to load GLUT-1 ASOs to enhance gene-silencing efficacy and its radiosensitization effects.

\subsection{Folate Receptor}

Werner et al. reported a polymeric nanoparticle formulation of docetaxel (Dtxl) targeted to the folate receptor (FT-NP Dtxl), and showed higher intracellular uptake by FR-overexpressing KB cells, compared to Dtxl or non-targeted NP Dtxl. Biocompatible and biodegradable poly lactic-co-glycolic acid (PLGA) nanoparticles encapsulated the hydrophobic Dtxl with lipids (lecithin), and lipid-PEG on the surface prevented protein adsorption, with the addition of a surface coating of folate.

The timing of radiotherapy after administration of the radiosensitizer was critical to achieve the maximum effect. In an in vitro study, free Dtxl had the greatest sensitization effect when radiation was given initially after drug administration, followed by a slow decrease over time, while the optimal timing of radiotherapy for FT-NP Dtxl was $24 \mathrm{~h}$ after drug administration, with the cytotoxicity being as effective as free Dtxl, possibly due to the delayed release of Dtxl from NPs. In an in vivo tumor model, FT-NP Dtxl produced the greatest sensitization effect when radiation was applied $12 \mathrm{~h}$ after systemic drug administration, and yielded better results than NP Dtxl and free Dtxl [144]. However, there was a rapid increase in tumor volume $\sim 20$ days after treatment; this is known as accelerated repopulation, due to cell-deathstimulated increased cell proliferation, which represents a serious problem in terms of tumor recurrence post-therapy [145].

\subsection{Epidermal growth factor receptor (EGFR)}

Increased expression of EGFR may play an important role in the enhanced cellular proliferation and angiogenic response after exposure to ionizing radiation, leading to RT resistance and/or recurrence [146]. Recent research has indicated significant effects of EGFR inhibitors as chemo- and radiosensitizers. A phase III randomized trial of EGFR inhibitors (CET) as radiosensitizers for locoregionally advanced head-and-neck cancer reported significantly increased survival [147].

Table 2. An outline of targeted nanodevices as radiosensitizers in head and neck cancer therapy

\begin{tabular}{llll}
\hline Targeting antigen & Nanoparticles & Radiosensitization & Ref. \\
\hline folate receptor & Polymeric NPs & FT-NP Dtxl & {$[144]$} \\
EGFR & PLGA NPs & antisense-EGFR NPs & Cet-targeted PTX-load carbon NPs \\
& Carbon NPs & (noncovalent assembly) & {$[149]$} \\
ATM & PLGA NPs & Antisense-ATM NPs & {$[150]$} \\
Hsp27 & lipofectamine & $\begin{array}{l}\text { lipofectamine-carried Hsp27 ASOs } \\
\text { lipofectamine-carried Hsp27 siRNA }\end{array}$ \\
MnSOD & Liposome & MnSOD-plasmid liposome & {$[156][157]$} \\
SphK1 & Au-NP & MnSOD-plasmid liposome+ Gefitinib & {$[162,163]$} \\
\hline
\end{tabular}

Abbreviations: NPs, nanoparticles; FR, folate receptor; Dtxl, docetaxel; EGFR, Epidermal growth factor receptor; PLGA, poly lactic-co-glycolic acid; Cet, Cetuximab; PTX, paclitaxel; ATM, ataxia-telangiectasia-mutated; MnSOD, manganese superoxide dismutase; SphK1, sphingoid base Sphingosine K1. 
Polymeric nanoparticles have also attracted a great deal of interest as potential nanocarriers due to their stability in various environments, the ability to load hydrophobic moieties, controlled drug release, inexpensive and convenient manufacture, and biodegradable properties $[18,148]$. The combination of radiotherapy and 24-h-pre-treatment EGFR-inhibition with antisense EGFR polymeric NPs showed a synergistic antitumor effect on the HNSCC SCCVII cell line [149]. PLGA NP-based antisense oligonucleotides targeting the ataxia-telangiectasia-mutated (ATM) gene were also preferentially taken up by SCCVII cells and induced radiosensitization [150].

CET and PTX enhance the radiotherapy sensitivity of HNSCC [151]. Sano et al. investigated the noncovalent assembly of CET-targeted PTX-loaded carbon nanoparticles (CET/PTX/PEG-HCCs) as radiosensitizers in OSC-19 and HN5 cells, and found significant inhibition of tumor growth in vivo and in vitro, compared to other treatment groups [104]. While CET/PTX/PEG-HCCs showed no significant difference compared to the other PTX treatment groups, the combination of CET/PTX/PEG-HCCs and radiation was significantly more effective.

\subsection{Heat shock protein 27 (Hsp27)}

Hsp27 is a "survival protein" that protects cells from stress stimuli, including heat shock and oxidative stress [152, 153]. High expression of Hsp27 is closely associated with tumorigenesis in various cancers including, breast, prostate, head-and-neck, and colon cancers, and is regarded as a prognostic factor for a poor outcome and therapeutic resistance [154, 155].

Aloy et al. demonstrated the protective role of Hsp27 against radiation-induced apoptosis, and presented the associated mechanisms; delayed redox status alteration and mitochondrial dysfunction. The radiosensitization effect of Hsp27 knockdown via Lipofectamine ${ }^{\circledR} 2000$-carried ASOs or siRNA in SQ20B cell lines was also investigated, and was characterized by over-expression of Hsp27, either constitutively or following irradiation. Both the antisense Hsp27 group and the siRNA-Hsp27 group showed positive results, while the siRNA-Hsp27 groups exhibited a greater decrease in Hsp27 expression and increased cell apoptosis, indicating that siRNA-Hsp27 induced greater radiosensitization [156]. An in vivo study confirmed the positive radiosensitive effects of second-generation ASOs targeted to Hsp27, in terms of enhanced radiation-induced SQ20B tumor regression and increased SQ20B survival in mice, without significant toxicity [157].

\subsection{Manganese superoxide dismutase (MnSOD)}

Radioprotective gene therapy via liposome-delivered MnSOD-plasmids (MnSOD-PL) can protect normal tissues but not tumors, with no adverse effect on the therapeutic response $[158,159]$. The mechanism may involve an antioxidant effect and decreased apoptosis [160, 161]. Application of MnSOD-PL gene therapy is at present undergoing clinical trials for the prevention of mucositis during HNSCC combination therapy.

Epperly et al. demonstrated the radiosensitive effect of MnSOD-PL in a CAL-33 orthotopic mouse-cheek tumor model, and showed that the EGFR antagonist, gefitinib (Iressa) further enhanced MnSOD-PL transfection-mediated radiosensitization of SCC-VII cells in vitro [162,163].

\subsection{Sphingosine kinase 1 (SphK1)}

Gold nanoparticles (Au-NPs) have been developed to form radiosensitizers [164]. Hainfeld et al. tested Au-NPs as radiosensitizers in a SCCVII model and showed a reduced tumor control dose 50\% (TCD50) and increased long-term survival. The data also indicated the effects of the radiation dose, beam energy and hyperthermia [165].

Au-NPs can serve as efficient carriers for many therapeutic agents, due to their convenient surface-modification, biocompatibility, enhanced cellular internalization, controlled payload release and non-toxicity [166]. In addition, the phenomenon of surface plasmon resonance (SPR) facilitates label-free monitoring of the distribution of these complexes [167].

Acylated sphingoid base ceramide (Cer) and sphingoid base sphingosine (Sph) are known tumor suppressor lipids that inhibit proliferation and promote apoptosis, while sphingosine-1-phosphate (S1P) exhibits the opposite effects. Sphingosine kinases (SphKs), such as SphK1, can phosphorylate Sph to form S1P, which contributes to maintenance of a dynamic equilibrium between cell proliferation and death [168]. Reduced levels of Cer and Sph, accompanied with increased levels of SphK1 and S1P, are implicated in various human cancers and are associated with anti-apoptotic phenotypes, tumor aggression and radioresistance; they are therefore regarded as new targets for cancer therapies [169]. Free-form siRNA molecules have a very short circulation time in the physiological environment due to their vulnerability to degradation and clearance. Masood et al. used gold nanorod (GNR) technology to deliver SphK siRNA into HNSCC cells, and found enhanced gene silencing efficiency and significant radiosensitization in vitro and in vivo, at a dosage $5 \times$ lower than that 
used commonly in pre-clinical RT. This experiment confirmed the radiosensitizing effects of Au-NPs, which were enhanced in combination with a SphK siRNA gene silencing strategy. Post-mortem analysis showed increased intracellular GNR-siRNA nanoplexes compared to GNR alone, while GNR was not detected in adjacent normal tissue, demonstrating its exclusive uptake by tumor tissues [170].

\section{Photothermal therapy (PTT)}

PTT is a localized, minimally invasive treatment using near-infrared (NIR). The concentrated light activation of a photosensitizer (PS), which accumulates preferentially in tumor tissues, induces a toxic photodynamic reaction to generate reactive oxygen species and active a cascading series of events, finally leading to oxidative damage and cell death [171].

A major advantage of PDT over chemo- or radiotherapy is that both PS and the irradiating light are themselves essentially inert and hence cause minimal systemic toxicity, which enables PDT to be used for repeated treatments of patients with HNSCC [172]. However, photo-toxicity arising from the unintentional systemic distribution of the PS and the efficacy of the treatment remain considerable problems in PDT. Foscan ${ }^{\circledR}$ is an ethanol/propylene glycol formulation of the PS temoporfin, and has been approved in Europe for the treatment of advanced and recurrent HNSCC. However, it failed to achieve FDA approval in the U.S. for the treatment of HNSCC due to poor tumor-selectivity and serious cutaneous burns [173]. Improvement of precise tumor-targeting is needed for a clinical application of PDT.

Schneider et al. reported two conjugates of FR-targeted tetraphenylporphyrin (TTP) as selective photosensitizers that displayed at least sevenfold greater uptake by KB nasopharyngeal cells compared to a TTP control [174]. Another selective photothermal therapy using anti-EGFR conjugated Au-NPs had been shown to be efficient in two oral squamous carcinoma cell lines (HSC 313 and HOC 3 Clone 8) [175]. More recently, the photosensitizer, silicon phthalocyanine-4 (Pc 4), was packaged in a polymeric micelles nanoplatform surfaced with GE11 peptides targeted to EGFR. The resulting EGFR-targeted Pc 4-nanoformulation was preferentially taken up by EGFR-positive H\&N SCC-15 cells and showed a significant anti-tumor effect in vitro and in vivo [176].

\section{Future perspectives}

Nanoparticle-based targeted therapeutics is a hot topic in cancer therapy. Though most approaches are still in the preclinical stages, they have shown tremendous potential to fulfill the need for viable alternative cancer therapies. Further research into high- er-specificity tumor targets and more efficient nano-carriers is needed, including complex modifications to enhance the antitumor efficacy, and to achieve the ultimate goal of personalized medicine.

\section{Acknowledgements}

This study was supported by the National Natural Science Foundation of China (grant nos. 81172562 and 81372903).

\section{Competing Interests}

The authors have declared that no competing interest exists.

\section{References}

1. Parkin DM, Bray F, Ferlay J, et al. Global cancer statistics, 2002. CA Cancer J Clin. 2005; 55: 74-108.

2. Ferlay J, Shin HR, Bray F, et al. Estimates of worldwide burden of cancer in 2008: GLOBOCAN 2008. Int J Cancer. 2010; 127: 2893-917.

3. Blot WJ, Mclaughlin JK, Winn DM, et al. Smoking And Drinking In Relation To Oral And Pharyngeal Cancer. Cancer Research. 1988; 48: 3282-7.

4. Hashibe M, Brennan P, Benhamou S, et al. Alcohol drinking in never users of tobacco, cigarette smoking in never drinkers, and the risk of head and neck cancer: Pooled analysis in the international head and neck cancer epidemiology consortium. Journal Of the National Cancer Institute. 2007; 99: 777-89.

5. D'Souza G, Kreimer AR, Viscidi R, et al. Case-control study of human papillomavirus and oropharyngeal cancer. N Engl J Med. 2007; 356: 1944-56.

6. Carvalho AL, Nishimoto IN, Califano JA, et al. Trends in incidence and prognosis for head and neck cancer in the United States: a site-specific analysis of the SEER database. Int J Cancer. 2005; 114: 806-16.

7. [Internet] Howlader N NA, Krapcho M, Garshell J, Miller D, Altekruse SF, Kosary CL, Yu M, Ruhl J, Tatalovich Z, Mariotto A, Lewis DR, Chen HS, Feuer EJ, Cronin KA. SEER Cancer Statistics Review, 1975-2011, National Cancer Institute, Bethesda, MD. http://seer.cancer.gov/csr/1975_2011/.

8. Forastiere A, Koch W, Trotti A, et al. Head and neck cancer. N Engl J Med. 2001; 345: 1890-900.

9. Lango, MN. Multimodal treatment for head and neck cancer. Surg Clin North Am. 2009; 89: 43-52.

10. Murphy BA, Gilbert J, Ridner SH. Systemic and global toxicities of head and neck treatment. Expert Rev Anticancer Ther. 2007; 7: 1043-53.

11. Maeda H Tumor-selective delivery of macromolecular drugs via the EPR effect: background and future prospects. Bioconjug Chem. 2010; 21: 797-802.

12. Dvorak HF. Leaky tumor vessels: consequences for tumor stroma generation and for solid tumor therapy. Prog Clin Biol Res. 1990; 354A: 317-30.

13. Kobayashi $H$, Watanabe R, Choyke PL. Improving conventional enhanced permeability and retention (EPR) effects; what is the appropriate target? Theranostics. 2013; 4: 81-9.

14. Peer D, Karp JM, Hong S, et al. Nanocarriers as an emerging platform for cancer therapy. Nature Nanotechnology. 2007; 2: 751-60.

15. Panyam J, Labhasetwar V. Biodegradable nanoparticles for drug and gene delivery to cells and tissue. Adv Drug Deliv Rev. 2003; 55: 329-47.

16. Redhead HM, Davis SS, Illum L. Drug delivery in poly(lactide-co-glycolide) nanoparticles surface modified with poloxamer 407 and poloxamine 908: in vitro characterisation and in vivo evaluation. J Control Release. 2001; 70: 353-63.

17. Muller RH, Maassen S, Weyhers H, et al. Phagocytic uptake and cytotoxicity of solid lipid nanoparticles (SLN) sterically stabilized with poloxamine 908 and poloxamer 407. J Drug Target. 1996; 4: 161-70.

18. De Rosa G, Quaglia F, La Rotonda MI, et al. Poly(lactide-co-glycolide) microspheres for the controlled release of oligonucleotide/polyethylenimine complexes. J Pharm Sci. 2002; 91: 790-9.

19. Bhadra D, Bhadra S, Jain P, et al. Pegnology: a review of PEG-ylated systems. Pharmazie. 2002; 57: 5-29.

20. Couvreur P, Barratt G, Fattal E, et al. Nanocapsule technology: a review. Crit Rev Ther Drug Carrier Syst. 2002; 19: 99-134.

21. Govender T, Stolnik S, Garnett MC, et al. PLGA nanoparticles prepared by nanoprecipitation: drug loading and release studies of a water soluble drug. J Control Release. 1999; 57: 171-85.

22. Govender T, Riley T, Ehtezazi T, et al. Defining the drug incorporation properties of PLA-PEG nanoparticles. Int J Pharm. 2000; 199: 95-110.

23. Panyam J, Williams D, Dash A, et al. Solid-state solubility influences encapsulation and release of hydrophobic drugs from PLGA/PLA nanoparticles. J Pharm Sci. 2004; 93: 1804-14.

24. Guzman LA, Labhasetwar V, Song C, et al. Local intraluminal infusion of biodegradable polymeric nanoparticles. A novel approach for prolonged drug delivery after balloon angioplasty. Circulation. 1996; 94: 1441-8. 
25. Xu H, Yao Q, Cai C, et al. Amphiphilic poly(amino acid) based micelles applied to drug delivery: The in vitro and in vivo challenges and the corresponding potential strategies. J Control Release. 2014;199C:84-97.

26. Messager L, Gaitzsch J, Chierico L, et al. Novel aspects of encapsulation and delivery using polymersomes. Curr Opin Pharmacol. 2014; 18C: 104-11.

27. Colley HE, Hearnden V, Avila-Olias M, et al. Polymersome-mediated delivery of combination anticancer therapy to head and neck cancer cells: 2D and 3D in vitro evaluation. Mol Pharm. 2014; 11: 1176-88.

28. McDevitt MR, Chattopadhyay D, Kappel BJ, et al. Tumor targeting with antibody-functionalized, radiolabeled carbon nanotubes. J Nucl Med. 2007; 48: $1180-9$

29. Gao Z, Zhang L, Sun Y. Nanotechnology applied to overcome tumor drug resistance. J Control Release. 2012; 162: 45-55.

30. Wagner E. Programmed drug delivery: nanosystems for tumor targeting. Expert Opin Biol Ther. 2007; 7: 587-93.

31. Stein CA, Cohen JS. Oligodeoxynucleotides as Inhibitors Of Gene-Expression a Review. Cancer Research. 1988; 48: 2659-68.

32. Wu HJ, Lima WF, Zhang $\mathrm{H}$, et al. Determination of the role of the human RNase H1 in the pharmacology of DNA-like antisense drugs. Journal Of Biological Chemistry. 2004; 279: 17181-9.

33. Dorn G, Abdel'al S, Natt FJC, et al. Specific inhibition of the rat ligand-gated ion channel P2X3 function via methoxyethoxy-modified phosphorothioated antisense oligonucleotides. Antisense \& Nucleic Acid Drug Development. 2001; 11: 165-74.

34. Chi KN, Siu LL, Hirte H, et al. A phase I study of OGX-011, a 2'-methoxyethyl phosphorothioate antisense to clusterin, in combination with docetaxel in patients with advanced cancer. Clin Cancer Res. 2008; 14: 833-9.

35. Sinn PL, Sauter SL, McCray Jr PB. Gene therapy progress and prospects: development of improved lentiviral and retroviral vectors--design, biosafety, and production. Gene Ther. 2005; 12: 1089-98.

36. Fenske DB, Cullis PR. Liposomal nanomedicines. Expert Opin Drug Deliv. 2008; 5: 25-44.

37. Nabel GJ, Nabel EG, Yang ZY, et al. Direct gene transfer with DNA-liposome complexes in melanoma: expression, biologic activity, and lack of toxicity in humans. Proc Natl Acad Sci U S A. 1993; 90: 11307-11.

38. Warburg O. On the origin of cancer cells. Science. 1956; 123: 309-14.

39. Nijsten MWN, van Dam GM. Hypothesis: Using the Warburg effect against cancer by reducing glucose and providing lactate. Medical Hypotheses. 2009; 73: $48-51$

40. Zhou, SH, Fan J, Chen XM, et al. Inhibition Of Cell Proliferation And Glucose Uptake In Human Laryngeal Carcinoma Cells by Antisense Oligonucleotides against Glucose Transporter-1. Head And Neck-Journal for the Sciences And Specialties Of the Head And Neck. 2009; 31: 1624-33.

41. Amann T, Maegdefrau U, Hartmann A, et al. GLUT1 Expression Is Increased in Hepatocellular Carcinoma and Promotes Tumorigenesis. American Journal Of Pathology. 2009; 174: 1544-52.

42. Shim BY, Jung JH, Lee KM, et al. Glucose transporter 1 (GLUT1) of anaerobic glycolysis as predictive and prognostic values in neoadjuvant chemoradiotherapy and laparoscopic surgery for locally advanced rectal cancer. International Journal Of Colorectal Disease. 2013; 28: 375-83.

43. Ramani P, Headford A, May MT. GLUT1 protein expression correlates with unfavourable histologic category and high risk in patients with neuroblastic tumours. Virchows Archiv. 2013; 462: 203-9.

44. Zhou SH, Wang SQ, Wu QL, et al. Expression of glucose transporter-1 and-3 in the head and neck carcinoma - The correlation of the expression with the biological behaviors. Orl-Journal for Oto-Rhino-Laryngology And Its Related Specialties. 2008; 70: 189-94.

45. Wu XH, Chen SP, Mao JY, et al. Expression and significance of hypoxia-inducible factor-1alpha and glucose transporter-1 in laryngeal carcinoma. Oncol Lett. 2013; 5: 261-6.

46. Deng D, Xu C, Sun $\mathrm{P}$, et al. Crystal structure of the human glucose transporter GLUT1. Nature. 2014; 510: 121-5.

47. Chen XM, Zhou SH, Fan J, et al. Construction and identification of an antisense glucose transporter-1 plasmid. J Int Med Res. 2008; 36: 1001-7.

48. He $\mathrm{Y}$, Zeng $\mathrm{O}$, Drenning $\mathrm{SD}$, et al. Inhibition of human squamous cell carcinoma growth in vivo by epidermal growth factor receptor antisense RNA transcribed from the U6 promoter. J Natl Cancer Inst. 1998; 90: 1080-7.

49. Rubin Grandis J, Zeng Q, Drenning SD. Epidermal growth factor receptor--mediated stat3 signaling blocks apoptosis in head and neck cancer. Laryngoscope. 2000; 110: 868-74.

50. Grandis JR, Drenning SD, Zeng Q, et al. Constitutive activation of Stat3 signaling abrogates apoptosis in squamous cell carcinogenesis in vivo. Proc Natl Acad Sci U S A. 2000; 97: 4227-32.

51. Thomas SM, Ogagan MJ, Freilino ML, et al. Antitumor mechanisms of systemically administered epidermal growth factor receptor antisense oligonucleotides in combination with docetaxel in squamous cell carcinoma of the head and neck. Mol Pharmacol. 2008; 73: 627-38.

52. Litchfield DW. Protein kinase CK2: structure, regulation and role in cellular decisions of life and death. Biochem J. 2003; 369: 1-15.

53. Trembley JH, Wang G, Unger G, et al. Protein kinase CK2 in health and disease: CK2: a key player in cancer biology. Cell Mol Life Sci. 2009; 66: 1858-67.

54. Ahmad KA, Wang G, Unger G, et al. Protein kinase CK2--a key suppressor of apoptosis. Adv Enzyme Regul. 2008; 48: 179-87.
55. Gapany M, Faust RA, Tawfic S, et al. Association of elevated protein kinase CK2 activity with aggressive behavior of squamous cell carcinoma of the head and neck. Mol Med. 1995; 1: 659-66.

56. Brown MS, Diallo OT, Hu M, et al. CK2 modulation of NF-kappaB, TP53, and the malignant phenotype in head and neck cancer by anti-CK2 oligonucleotides in vitro or in vivo via sub-50-nm nanocapsules. Clin Cancer Res. 2010; 16: 2295-307.

57. Todaro GJ, Fryling C, De Larco JE. Transforming growth factors produced by certain human tumor cells: polypeptides that interact with epidermal growth factor receptors. Proc Natl Acad Sci U S A. 1980; 77: 5258-62.

58. Grandis JR, Tweardy DJ. Elevated Levels Of Transforming Growth-Factor-Alpha And Epidermal Growth-Factor Receptor Messenger-Rna Are Early Markers Of Carcinogenesis In Head And Neck-Cancer. Cancer Research. 1993; 53: 3579-84.

59. Rubin Grandis J, Melhem MF, Gooding WE, et al. Levels of TGF-alpha and EGFR protein in head and neck squamous cell carcinoma and patient survival. J Natl Cancer Inst. 1998; 90: 824-32.

60. Grandis JR, Chakraborty A, Zeng Q, et al. Downmodulation of TGF-alpha protein expression with antisense oligonucleotides inhibits proliferation of head and neck squamous carcinoma but not normal mucosal epithelial cells. Journal Of Cellular Biochemistry. 1998; 69: 55-62.

61. Endo S, Zeng Q, Burke NA, et al. TGF-alpha antisense gene therapy inhibits head and neck squamous cell carcinoma growth in vivo. Gene Ther. 2000; 7: 1906-14.

62. Ambrosini G, Adida C, Altieri DC. A novel anti-apoptosis gene, survivin, expressed in cancer and lymphoma. Nat Med. 1997; 3: 917-21.

63. Yamamoto $\mathrm{H}, \mathrm{Ngan} \mathrm{CY}$, Monden M. Cancer cells survive with survivin. Cancer Sci. 2008; 99: 1709-14.

64. Dong Y, Sui L, Watanabe Y, et al. Survivin expression in laryngeal squamous cell carcinomas and its prognostic implications. Anticancer Res. 2002; 22: 2377-83

65. Pickhard A, Grober S, Haug AK, et al. Survivin and pAkt as potential prognostic markers in squamous cell carcinoma of the head and neck. Oral Surg Oral Med Oral Pathol Oral Radiol. 2014; 117: 733-42.

66. Xiang C, Liu WS, Jia SS. [Effect of survivin antisense oligodeoxynucleotide on carcinoma of larynx in vivo and in vitro]. Zhonghua Er Bi Yan Hou Tou Jing Wai Ke Za Zhi. 2006; 41: 60-4.

67. Fire A, Xu S, Montgomery MK, et al. Potent and specific genetic interference by double-stranded RNA in Caenorhabditis elegans. Nature. 1998; 391: 806-11.

68. Hammond SM, Caudy AA, Hannon GJ. Post-transcriptional gene silencing by double-stranded RNA. Nat Rev Genet. 2001; 2: 110-9.

69. Hammond SM, Bernstein E, Beach D, et al. An RNA-directed nuclease mediates post-transcriptional gene silencing in Drosophila cells. Nature. 2000; 404: 293-6.

70. Zamore PD, Tuschl T, Sharp PA, et al. RNAi: Double-stranded RNA directs the ATP-dependent cleavage of mRNA at 21 to 23 nucleotide intervals. Cell. 2000; 101: 25-33

71. Elbashir SM, Harborth J, Lendeckel W, et al. Duplexes of 21-nucleotide RNAs mediate RNA interference in cultured mammalian cells. Nature. 2001; 411: 494-8

72. Bertrand JR, Pottier M, Vekris A, et al. Comparison of antisense oligonucleotides and siRNAs in cell culture and in vivo. Biochem Biophys Res Commun. 2002; 296: 1000-4

73. $\mathrm{Xu}$ Y, Linde A, Larsson $\mathrm{O}$, et al. Functional comparison of single- and double-stranded siRNAs in mammalian cells. Biochem Biophys Res Commun. 2004; 316: 680-7.

74. Holen T, Amarzguioui M, Babaie E, et al. Similar behaviour of single-strand and double-strand siRNAs suggests they act through a common RNAi pathway. Nucleic Acids Research. 2003; 31: 2401-2407.

75. Grimm D. Small silencing RNAs: state-of-the-art. Adv Drug Deliv Rev. 2009; 61: 672-703.

76. Whitehead, KA, R Langer and DG Anderson Knocking down barriers: advances in siRNA delivery. Nat Rev Drug Discov. 2009; 8: 129-38.

77. Deng Y, Wang CC, Choy KW, et al. Therapeutic potentials of gene silencing by RNA interference: principles, challenges, and new strategies. Gene. 2014; 538: 217-27.

78. Huh MS, Lee SY, Park S, et al. Tumor-homing glycol chitosan/polyethylenimine nanoparticles for the systemic delivery of siRNA in tumor-bearing mice. J Control Release. 2010; 144: 134-43.

79. Kim SW, Kim NY, Bin Choi Y, et al. RNA interference in vitro and in vivo using an arginine peptide/siRNA complex system. Journal Of Controlled Release. 2010; 143: 335-43.

80. Zimmermann M, Zouhair A, Azria D, et al. The epidermal growth factor receptor (EGFR) in head and neck cancer: its role and treatment implications. Radiat Oncol. 2006; 1: 11.

81. Ang KK, Berkey BA, Tu XY, et al. Impact of epidermal growth factor receptor expression on survival and pattern of relapse in patients with advanced head and neck carcinoma. Cancer Research. 2002; 62: 7350-56.

82. Choong NW, Cohen EE. Epidermal growth factor receptor directed therapy in head and neck cancer. Crit Rev Oncol Hematol. 2006; 57: 25-43.

83. Cho HJ, Chong S, Chung SJ, et al. Poly-L-arginine and Dextran Sulfate-Based Nanocomplex for Epidermal Growth Factor Receptor (EGFR) siRNA Delivery: Its Application for Head and Neck Cancer Treatment. Pharmaceutical Research. 2012; 29: 1007-19. 
84. Eriksson S, Graslund A, Skog S, et al. Cell cycle-dependent regulation of mammalian ribonucleotide reductase. The $S$ phase-correlated increase in subunit M2 is regulated by de novo protein synthesis. J Biol Chem. 1984; 259: 11695-700.

85. Engstrom Y, Eriksson S, Jildevik I, et al. Cell cycle-dependent expression of mammalian ribonucleotide reductase. Differential regulation of the two subunits. J Biol Chem. 1985; 260: 9114-6.

86. Cerqueira NM, Pereira S, Fernandes PA, et al. Overview of ribonucleotide reductase inhibitors: an appealing target in anti-tumour therapy. Curr Med Chem. 2005; 12: 1283-94.

87. Davis ME. The first targeted delivery of siRNA in humans via a self-assembling, cyclodextrin polymer-based nanoparticle: from concept to clinic. Mol Pharm. 2009; 6: 659-68.

88. Gatter KC, Brown G, Trowbridge IS, et al. Transferrin Receptors In Human-Tissues - Their Distribution And Possible Clinical Relevance. Journal Of Clinical Pathology. 1983; 36: 539-45.

89. Bartlett DW, Su H, Hildebrandt IJ, et al. Impact of tumor-specific targeting on the biodistribution and efficacy of siRNA nanoparticles measured by multimodality in vivo imaging. Proceedings Of the National Academy Of Sciences Of the United States Of America. 2007; 104: 15549-54.

90. Rahman MA, Amin AR, Wang X, et al. Systemic delivery of siRNA nanoparticles targeting RRM2 suppresses head and neck tumor growth. J Control Release. 2012; 159: 384-92.

91. Rahman MA, Amin RMR, Wang DS, et al. RRM2 Regulates Bcl-2 in Head and Neck and Lung Cancers: A Potential Target for Cancer Therapy. Clinical Cancer Research. 2013; 19: 3416-28.

92. Adrain C, Zettl M, Christova $Y$, et al. Tumor necrosis factor signaling requires iRhom 2 to promote trafficking and activation of TACE. Science. 2012; 335: $225-8$

93. Ren $\mathrm{X}$, Song $\mathrm{W}$, Liu $\mathrm{W}$, et al. Rhomboid domain containing 1 inhibits cell apoptosis by upregulating AP-1 activity and its downstream target Bcl-3. FEBS Lett. 2013; 587: 1793-8.

94. Wang Y, Guan X, Fok KL, et al. A novel member of the Rhomboid family, RHBDD1, regulates BIK-mediated apoptosis. Cell Mol Life Sci. 2008; 65: $3822-9$

95. Jeyaraju DV, Xu L, Letellier MC, et al. Phosphorylation and cleavage of presenilin-associated rhomboid-like protein (PARL) promotes changes in mitochondrial morphology. Proc Natl Acad Sci U S A. 2006; 103: 18562-7.

96. Fleig L, Bergbold N, Sahasrabudhe P, et al. Ubiquitin-dependent intramembrane rhomboid protease promotes ERAD of membrane proteins. Mol Cell. 2012; 47: 558-69.

97. Lin YN, Gui FM, Shen H, et al. [Expression of RHBDD1 gene in patients with chronic myeloid leukemia and its clinical significance]. Zhongguo Shi Yan Xue Ye Xue Za Zhi. 2013; 21: 12-5.

98. Abba MC, Lacunza E, Nunez MI, et al. Rhomboid domain containing 2 (RHBDD2): a novel cancer-related gene over-expressed in breast cancer. Biochim Biophys Acta. 2009; 1792: 988-97.

99. Wei $\mathrm{X}, \mathrm{Lv} \mathrm{T}, \mathrm{Chen} \mathrm{D}$, et al. Lentiviral vector mediated delivery of RHBDD1 shRNA down regulated the proliferation of human glioblastoma cells. Technol Cancer Res Treat. 2014; 13: 87-93.

100. Nakagawa T, Guichard A, Castro $C P$, et al. Characterization of a human rhomboid homolog, p100hRho/RHBDF1, which interacts with TGF-alpha family ligands. Dev Dyn. 2005; 233: 1315-31.

101. Yan Z, Zou H, Tian F, et al. Human rhomboid family-1 gene silencing causes apoptosis or autophagy to epithelial cancer cells and inhibits xenograft tumor growth. Mol Cancer Ther. 2008; 7: 1355-64.

102. Zou H, Thomas SM, Yan ZW, et al. Human rhomboid family-1 gene RHBDF1 participates in GPCR-mediated transactivation of EGFR growth signals in head and neck squamous cancer cells. FASEB J. 2009; 23: 425-32.

103. Berlin JM, Pham TT, Sano D, et al. Noncovalent functionalization of carbon nanovectors with an antibody enables targeted drug delivery. ACS Nano. 2011; 5: 6643-50

104. Sano D, Berlin JM, Pham TT, et al. Noncovalent assembly of targeted carbon nanovectors enables synergistic drug and radiation cancer therapy in vivo. ACS Nano. 2012; 6: 2497-505.

105. Altintas I, Heukers R, van der Meel R, et al. Nanobody-albumin nanoparticles (NANAPs) for the delivery of a multikinase inhibitor 17864 to EGFR overexpressing tumor cells. J Control Release. 2013; 165: 110-8.

106. Pinto HA, Jacobs $C$. Chemotherapy for recurrent and metastatic head and neck cancer. Hematol Oncol Clin North Am. 1991; 5: 667-86.

107. Jacobs C, Lyman G, Velezgarcia E, et al. A Phase-lii Randomized Study Comparing Cisplatin And Fluorouracil as Single Agents And In Combination for Advanced Squamous-Cell Carcinoma Of the Head And Neck. Journal Of Clinical Oncology. 1992; 10: 257-63.

108. Zhou HF, Liu XD, Guo X, et al. Synthesis and characterization of amphiphilic chitosan derivatives as a nano-carrier for paclitaxel delivery. Journal Of Controlled Release. 2011; 152: E124-5.

109. Elnakat H, Ratnam M. Distribution, functionality and gene regulation of folate receptor isoforms: implications in targeted therapy. Adv Drug Deliv Rev. 2004; 56: 1067-84

110. Leamon CP, Reddy JA. Folate-targeted chemotherapy. Adv Drug Deliv Rev. 2004; 56: 1127-41.

111. Zhao X, Li H, Lee RJ. Targeted drug delivery via folate receptors. Expert Opin Drug Deliv. 2008; 5: 309-19.
112. Saba NF, Wang $X$, Muller $S$, et al. Examining Expression Of Folate Receptor In Squamous Cell Carcinoma Of the Head And Neck as a Target for a Novel Nanotherapeutic Drug. Head And Neck-Journal for the Sciences And Specialties Of the Head And Neck. 2009; 31: 475-81.

113. Wang X, Li J, Wang Y, et al. HFT-T, a targeting nanoparticle, enhances specific delivery of paclitaxel to folate receptor-positive tumors. ACS Nano. 2009; 3: 3165-74

114. Ward BB, Dunham T, Majoros IJ, et al. Targeted dendrimer chemotherapy in an animal model for head and neck squamous cell carcinoma. J Oral Maxillofac Surg. 2011; 69: 2452-9.

115. Xie M, Zhang $\mathrm{H}, \mathrm{Xu} \mathrm{Y}$, et al. Expression of folate receptors in nasopharyngeal and laryngeal carcinoma and folate receptor-mediated endocytosis by molecular targeted nanomedicine. Int J Nanomedicine. 2013; 8: 2443-51.

116. Dosio F, Brusa P, Crosasso P, et al. Preparation, characterization and properties in vitro and in vivo of a paclitaxel-albumin conjugate. Journal Of Controlled Release. 1997; 47: 293-304.

117. Dosio F, Arpicco S, Brusa P, et al. Poly(ethylene glycol)-human serum albumin-paclitaxel conjugates: preparation, characterization and pharmacokinetics. J Control Release. 2001; 76: 107-17.

118. Dosio F, Arpicco S, Stella B, et al. Folate-mediated targeting of albumin conjugates of paclitaxel obtained through a heterogeneous phase system. International Journal Of Pharmaceutics. 2009; 382: 117-23.

119. Bhirde AA, Patel V, Gavard J, et al. Targeted killing of cancer cells in vivo and in vitro with EGF-directed carbon nanotube-based drug delivery. ACS Nano. 2009; 3: 307-16.

120. Liu Z, Cai W, He L, et al. In vivo biodistribution and highly efficient tumour targeting of carbon nanotubes in mice. Nat Nanotechnol. 2007; 2: 47-52.

121. Berlin JM, Leonard AD, Pham TT, et al. Effective drug delivery, in vitro and in vivo, by carbon-based nanovectors noncovalently loaded with unmodified Paclitaxel. ACS Nano. 2010; 4: 4621-36.

122. He L, Torres-Lockhart K, Forster N, et al. Mcl-1 and FBW7 control a dominant survival pathway underlying $\mathrm{HDAC}$ and $\mathrm{Bcl}-2$ inhibitor synergy in squamous cell carcinoma. Cancer Discov. 2013; 3: 324-37.

123. Chang RS, Suh MS, Kim S, et al. Cationic drug-derived nanoparticles for multifunctional delivery of anticancer siRNA. Biomaterials. 2011; 32: 9785-95.

124. Yu YH, Kim E, Park DE, et al. Cationic solid lipid nanoparticles for co-delivery of paclitaxel and siRNA. Eur J Pharm Biopharm. 2012; 80: 268-73.

125. Shim G, Han SE, Yu YH, et al. Trilysinoyl oleylamide-based cationic liposomes for systemic co-delivery of siRNA and an anticancer drug. J Control Release. 2011; 155: 60-6.

126. Wang D, Boerner SA, Winkler JD, et al. Clinical experience of MEK inhibitors in cancer therapy. Biochim Biophys Acta. 2007; 1773: 1248-55.

127. Elser C, Siu LL, Winquist E, et al. Phase II trial of sorafenib in patients with recurrent or metastatic squamous cell carcinoma of the head and neck or nasopharyngeal carcinoma. J Clin Oncol. 2007; 25: 3766-73.

128. Kang SH, Cho HJ, Shim G, et al. Cationic liposomal co-delivery of small interfering RNA and a MEK inhibitor for enhanced anticancer efficacy. Pharm Res. 2011; 28: 3069-78.

129. Niwa H, Wentzel AL, Li M, et al. Antitumor effects of epidermal growth factor receptor antisense oligonucleotides in combination with docetaxel in squamous cell carcinoma of the head and neck. Clin Cancer Res. 2003; 9: 5028-35.

130. Riedel F, Gotte K, Goessler U, et al. Targeting chemotherapy-induced VEGF up-regulation by VEGF antisense oligonucleotides in HNSCC cell lines. Anticancer Res. 2004; 24: 2179-83.

131. Liu S, Jin F, Dai W, et al. Antisense treatment of IGF-IR enhances chemosensitivity in squamous cell carcinomas of the head and neck. Eur J Cancer. 2010; 46: 1744-51.

132. Skoda C, Erovic BM, Wachek V, et al. Down-regulation of Mcl-1 with antisense technology alters the effect of various cytotoxic agents used in treatment of squamous cell carcinoma of the head and neck. Oncology Reports. 2008; 19: 1499-503.

133. Rait AS, Pirollo KF, Ulick D, et al. HER-2-targeted antisense oligonucleotide results in sensitization of head and neck cancer cells to chemotherapeutic agents. Ann N Y Acad Sci. 2003; 1002: 78-89.

134. Fetz V, Bier C, Habtemichael N, et al. Inducible NO synthase confers chemoresistance in head and neck cancer by modulating survivin. International Journal Of Cancer. 2009; 124: 2033-41.

135. Chitapanarux I, Lorvidhaya V, Tharavichitkul E, et al. A phase II study of docetaxel and carboplatin with concurrent radiation therapy for locally advanced head and neck cancer. Auris Nasus Larynx. 2011; 38: 108-13.

136. Karasawa K, Shinoda H, Katsui K, et al. Radiotherapy with concurrent docetaxel and carboplatin for head and neck cancer. Anticancer Res. 2002; 22: $3785-8$

137. Zhao K, Yang SY, Zhou SH, et al. Fluorodeoxyglucose uptake in laryngeal carcinoma is associated with the expression of glucose transporter-1 and hypoxia-inducible-factor-1 alpha and the phosphoinositide 3-kinase/protein kinase B pathway. Oncology Letters. 2014; 7: 984-990.

138. Alakus H, Batur M, Schmidt M, et al. Variable F-18-fluorodeoxyglucose uptake in gastric cancer is associated with different levels of GLUT-1 expression. Nuclear Medicine Communications. 2010; 31: 532-538.

139. Han MW, Lee HJ, Cho KJ, et al. Role of FDG-PET as a biological marker for predicting the hypoxic status of tongue cancer. Head And Neck-Journal for the Sciences And Specialties Of the Head And Neck. 2012; 34: 1395-402. 
140. Rademakers SE, Lok J, van der Kogel AJ, et al. Metabolic markers in relation to hypoxia; staining patterns and colocalization of pimonidazole, HIF-1alpha, CAIX, LDH-5, GLUT-1, MCT1 and MCT4. BMC Cancer. 2011; 11: 167.

141. Kunkel M, Moergel M, Stockinger M, et al. Overexpression of GLUT-1 is associated with resistance to radiotherapy and adverse prognosis in squamous cell carcinoma of the oral cavity. Oral Oncology. 2007; 43: 796-803.

142. De Schutter $H$, Landuyt $W$, Verbeken $E$, et al. The prognostic value of the hypoxia markers CA IX and GLUT I and the cytokines VEGF and IL 6 in head and neck squamous cell carcinoma treated by radiotherapy chemotherapy. Bmc Cancer. 2005; 5:42.

143. Yan SX, Luo XM, Zhou SH, et al. Effect of antisense oligodeoxynucleotides glucose transporter-1 on enhancement of radiosensitivity of laryngeal carcinoma. Int J Med Sci. 2013; 10: 1375-86.

144. Werner ME. Folate-Targeted Polymeric Nanoparticle Formulation of Docetaxel Is an Effective with Efficacy Dependent on the Timing Molecularly Targeted Radiosensitizer of Radiotherapy. American Chemical Society. 2011;5:8990-8.

145. Kim JJ, Tannock IF. Repopulation of cancer cells during therapy: an important cause of treatment failure. Nat Rev Cancer. 2005; 5: 516-25.

146. Schmidt-Ullrich RK, Valerie KC, Chan W, et al. Altered expression of epidermal growth factor receptor and estrogen receptor in MCF-7 cells after single and repeated radiation exposures. Int J Radiat Oncol Biol Phys. 1994; 29: 813-9.

147. Bonner JA, Harari PM, Giralt J, et al. Radiotherapy plus cetuximab for locoregionally advanced head and neck cancer: 5-year survival data from a phase 3 randomised trial, and relation between cetuximab-induced rash and survival. Lancet Oncol. 2010; 11: 21-8.

148. Lu JM, Wang X, Marin-Muller C, et al. Current advances in research and clinical applications of PLGA-based nanotechnology. Expert Rev Mol Diagn. 2009; 9: 325-41

149. Ping Y, Jian Z, Yi Z, et al. Inhibition of the EGFR with nanoparticles encapsulating antisense oligonucleotides of the EGFR enhances radiosensitivity in SCCVII cells. Med Oncol. 2010; 27: 715-21.

150. Zou J, Qiao XM, Ye HP, et al. Inhibition of Ataxia-Telangiectasia Mutated by Antisense Oligonucleotide Nanoparticles Induces Radiosensitization of Head and Neck Squamous-Cell Carcinoma in Mice. Cancer Biotherapy And Radiopharmaceuticals. 2009; 24: 339-46.

151. Bonner JA, Harari PM, Giralt J, et al. Radiotherapy plus cetuximab for squamous-cell carcinoma of the head and neck. N Engl J Med. 2006; 354: 567-78.

152. Gabai VL, Sherman MY. Invited Review: Interplay between molecular chaperones and signaling pathways in survival of heat shock. Journal Of Applied Physiology. 2002; 92: 1743-1748.

153. Arrigo AP. Hsp27: novel regulator of intracellular redox state. IUBMB Life. 2001; 52: 303-7.

154. Calderwood SK, Khaleque MA, Sawyer DB, et al. Heat shock proteins in cancer: chaperones of tumorigenesis. Trends Biochem Sci. 2006; 31: 164-72.

155. Lo Muzio L, Leonardi R, Mariggio MA, et al. HSP 27 as possible prognostic factor in patients with oral squamous cell carcinoma. Histology And Histopathology. 2004; 19: 119-28.

156. Aloy MT, Hadchity E, Bionda C, et al. Protective role of Hsp27 protein against gamma radiation-induced apoptosis and radiosensitization effects of Hsp27 gene silencing in different human tumor cells. Int J Radiat Oncol Biol Phys. 2008; 70: 543-53.

157. Hadchity E, Aloy MT, Paulin C, et al. Heat Shock Protein 27 as a New Therapeutic Target for Radiation Sensitization of Head and Neck Squamous Cell Carcinoma. Molecular Therapy. 2009; 17: 1387-94.

158. Epperly MW, Defilippi S, Sikora C, et al. Intratracheal injection of manganese superoxide dismutase (MnSOD) plasmid/liposomes protects normal lung but not orthotopic tumors from irradiation. Gene Therapy. 2000; 7: 1011-18

159. Guo H, Seixas-Silva JA, Jr., Epperly MW, et al. Prevention of radiation-induced oral cavity mucositis by plasmid/liposome delivery of the human manganese superoxide dismutase (SOD2) transgene. Radiat Res. 2003; 159: 361-70.

160. Epperly MW, Wegner R, Kanai AJ, et al. Effects of MnSOD-plasmid liposome gene therapy on antioxidant levels in irradiated murine oral cavity orthotopic tumors. Radiat Res. 2007; 167: 289-97.

161. Epperly MW, Carpenter M, Agarwal A, et al. Intraoral manganese superoxide dismutase-plasmid/liposome (MnSOD-PL) radioprotective gene therapy decreases ionizing irradiation-induced murine mucosal cell cycling and apoptosis. In Vivo. 2004; 18: 401-10.

162. Epperly MW, Lai SY, Kanai AJ, et al. Effectiveness of combined modality radiotherapy of orthotopic human squamous cell carcinomas in $\mathrm{Nu} / \mathrm{Nu}$ mice using cetuximab, tirapazamine and MnSOD-plasmid liposome gene therapy. In Vivo. 2010; 24: 1-8.

163. Epperly MW, Franicola D, Zhang X, et al. Effect of EGFR antagonists gefitinib (Iressa) and C225 (Cetuximab) on MnSOD-plasmid liposome transgene radiosensitization of a murine squamous cell carcinoma cell line. In Vivo. 2006; 20: $791-6$

164. Hainfeld JF, Dilmanian FA, Slatkin DN, et al. Radiotherapy enhancement with gold nanoparticles. J Pharm Pharmacol. 2008; 60: 977-85.

165. Hainfeld JF, Dilmanian FA, Zhong Z, et al. Gold nanoparticles enhance the radiation therapy of a murine squamous cell carcinoma. Phys Med Biol. 2010; 55: 3045-59.

166. Pissuwan D, Niidome T, Cortie MB. The forthcoming applications of gold nanoparticles in drug and gene delivery systems. J Control Release. 2011; 149: 65-71.
167. Bedford EE, Spadavecchia J, Pradier CM, et al. Surface Plasmon Resonance Biosensors Incorporating Gold Nanoparticles. Macromolecular Bioscience. 2012; 12: 724-39.

168. Maceyka M, Payne SG, Milstien S, et al. Sphingosine kinase, sphingosine-1-phosphate, and apoptosis. Biochim Biophys Acta. 2002; 1585: 193-201.

169. Ogretmen B, Hannun YA. Biologically active sphingolipids in cancer pathogenesis and treatment. Nat Rev Cancer. 2004; 4: 604-16.

170. Masood R, Roy I, Zu S, et al. Gold nanorod-sphingosine kinase siRNA nanocomplexes: a novel therapeutic tool for potent radiosensitization of head and neck cancer. Integr Biol (Camb). 2012; 4: 132-41.

171. Allison RR. Photodynamic therapy: oncologic horizons. Future Oncol. 2014; 10: $123-4$.

172. Miller JD, Baron ED, Scull H, et al. Photodynamic therapy with the phthalocyanine photosensitizer Pc 4: the case experience with preclinical mechanistic and early clinical-translational studies. Toxicol Appl Pharmacol. 2007; 224: 290-9.

173. Allison RR, Mota HC, Sibata CH. Clinical PD/PDT in North America: An historical review. Photodiagnosis And Photodynamic Therapy. 2004; 1: 263-77.

174. Schneider RL, Schmitt F, Frochot C, et al. Design, synthesis, and biological evaluation of folic acid targeted tetraphenylporphyrin as novel photosensitizers for selective photodynamic therapy. Bioorganic \& Medicinal Chemistry. 2005; 13 : 2799-808.

175. El-Sayed IH, Huang XH, El-Sayed MA. Selective laser photo-thermal therapy of epithelial carcinoma using anti-EGFR antibody conjugated gold nanopartiles. Cancer Letters. 2006; 239: 129-35.

176. Master A, Malamas A, Solanki R, et al. A cell-targeted photodynamic nanomedicine strategy for head and neck cancers. Mol Pharm. 2013; 10: 1988-97.

177. Siegel R, Naishadham D, Jemal A. Cancer statistics, 2013. CA Cancer J Clin. 2013; 63: 11-30. 